\title{
Pothea furtadoi sp. nov. (Hemiptera, Heteroptera, Reduviidae, Ectrichodiinae) de Mato Grosso e Minas Gerais, Brasil
}

\author{
Hélcio R. Gil-Santana' \& Luiz A. A. Costa ${ }^{2}$ \\ ${ }^{1}$ Departamento de Entomologia, Instituto Oswaldo Cruz. Avenida Brasil 4365, Manguinhos, 21045-900 Rio de Janeiro, Rio \\ de Janeiro, Brasil. E-mail: helciogil@uol.com.br \\ ${ }^{2}$ Museu Nacional, Universidade Federal do Rio de Janeiro. Quinta da Boa Vista, 20940-040 Rio de Janeiro, Rio de Janeiro, \\ Brasil.
}

\begin{abstract}
Pothea furtadoi sp. nov. (Hemiptera, Heteroptera, Reduviidae, Ectrichodiinae) from Mato Grosso and Minas Gerais, Brazil. A new species of the genus Pothea Amyot \& Serville, 1843, from Mato Grosso and Minas Gerais, is described and illustrated.
\end{abstract}

KEY WORDS. New species, Neotropical.

RESUMO. Uma nova espécie do gênero Pothea Amyot \& Serville, 1843,de Mato Grosso e Minas Gerais, Brasil é descrita e ilustrada.

PALAVRAS CHAVES. Nova espécie, neotropical.

Ectrichodiinae apresenta atualmente 17 gêneros e 111 espécies nas Américas (CARPintero \& Maldonado Capriles 1996). DOUgherty (1995), em revisão recente de Ectrichodiinae do Novo Mundo, relacionou 19 gêneros válidos, alguns em discordância com os aceitos por Carpintero \& Maldonado Capriles (1996).

A espécie-tipo de Pothea Amyot \& Serville, 1843, Reduvius ventralis Lepeletier \& Serville, 1825, foi fixada subseqüentemente por van DuzeE (1916).

Pothea é exclusivo do Novo Mundo, com a grande maioria das espécies habitando a Região Neotropical e somente uma na Região Neártica (Putshrov \& Putshrov 1985). Embora se tenha atribuído a sua distribuição dos Estados Unidos da América à Argentina (Champion 1899, Carpintero \& Maldonado Capriles 1996), só há uma espécie referida para os EUA (P. aeneonitens) (STÅl 1864, 1872, Lethierry \& Severin 1896, Maldonado Capriles 1990), referência esta que foi tida como provavelmente errônea por Wygodzinsky (1949), CARPintero (1978) e CARPINTERo \& Maldonado Capriles (1990) e ignorada por Dougherty (1995), que considerou P. aeneonitens como procedente do Peru. Ressalte-se, por oportuno, que SEHNAL (2000) ao reexaminar o material-tipo dessa espécie, proveniente da Coleção Signoret, atualmente depositada no Museu de Viena, Áustria, registrou que na etiqueta de procedência do síntipo macho lê-se: "Nordamer./ Coll. Signoret", demonstrando que se algum engano aconteceu, o mesmo não foi do autor de P. aeneonitens (STÅL 1864). Por outro lado, várias espécies ocorrem no México (CHAMPION 1899, Wygodzinsky 1949, Carpintero 1978, 1980, Maldonado CAPRILEs 1990, Dougherty 1995), país que pode ser seguramente considerado o limite Norte de distribuição das espécies de Pothea. Enquanto o limite Sul é a Argentina (CARPINTERo 1978,
1980, Maldonado Capriles 1990, Dougherty 1995), ressalvou-se a sua ausência no Chile; nas Antilhas só aparecendo em Cuba (Carpintero \& Maldonado Capriles 1996).

\section{Pothea furtadoi sp. nov.}

Descrição. Holótipo. Macho. Dimensões (em milímetros). Corpo: comprimento 21. Cabeça: comprimento 4,2; largura total (incluindo os olhos) 2,3; largura entre os olhos 0,9; porção anteocular 1,8; porção pós-ocular (incluindo o colo) 2,0; antena segmento I 2,5; segmento II 4,0; segmento III 1,9; segmento IV 1,3; segmento V 0,9 ; segmento VI 0,6 ; segmento VII 0,5 ; segmento VIII 0,7; comprimento total 4,8; segmento I 3,4; segmento II 1,0; segmento III 0,4. Tórax: lobo anterior do pronoto: comprimento 1,6; largura 2,5; lobo posterior do pronoto: comprimento 3,9; largura 5,6; comprimento do escutelo 2,1; largura do escutelo 2,5; comprimento do hemiélitro 13,5 ; pernas anteriores fêmur: 4,5; tíbia 4,6; tarso 1,6; pernas médias: fêmur 4,6; tíbia 5,2; tarso 1,8; pernas posteriores: fêmur 5,9; tíbia 7,0; tarso 1,9. Abdome: comprimento 12,0; largura 7,0.

Superfície corporal lisa e glabra. Coloração geral vermelha (Fig. 1), com marcações escurecidas a negras.

Cabeça (Figs 3 e 4) alongada, vermelha ou vermelho-rósea com olhos enegrecidos e proeminentes, apresentando uma pequena mácula escura na frente de cada ocelo; tubérculo ocelar elevado; clípeo com espinho dorsal; rostro alongado, com o ápice do primeiro segmento, em vista lateral, ultrapassando o nível do tubérculo ocelar. Antenas com oito segmentos cilíndricos, escurecidos com a base mais clara, apresentando pêlos curtos e longos, estes mais esparsos nos segmentos V-VIII. 

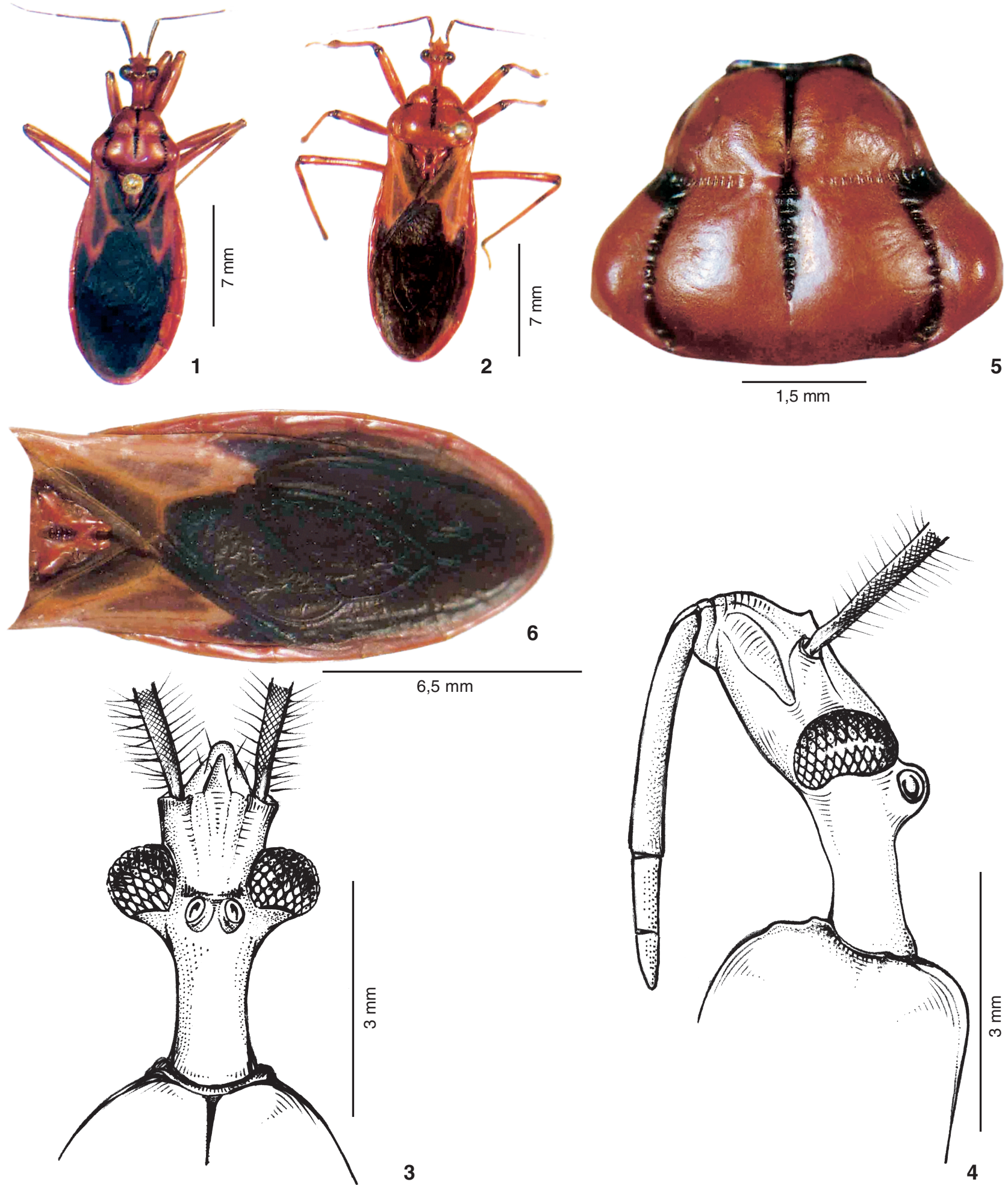

$6,5 \mathrm{~mm}$

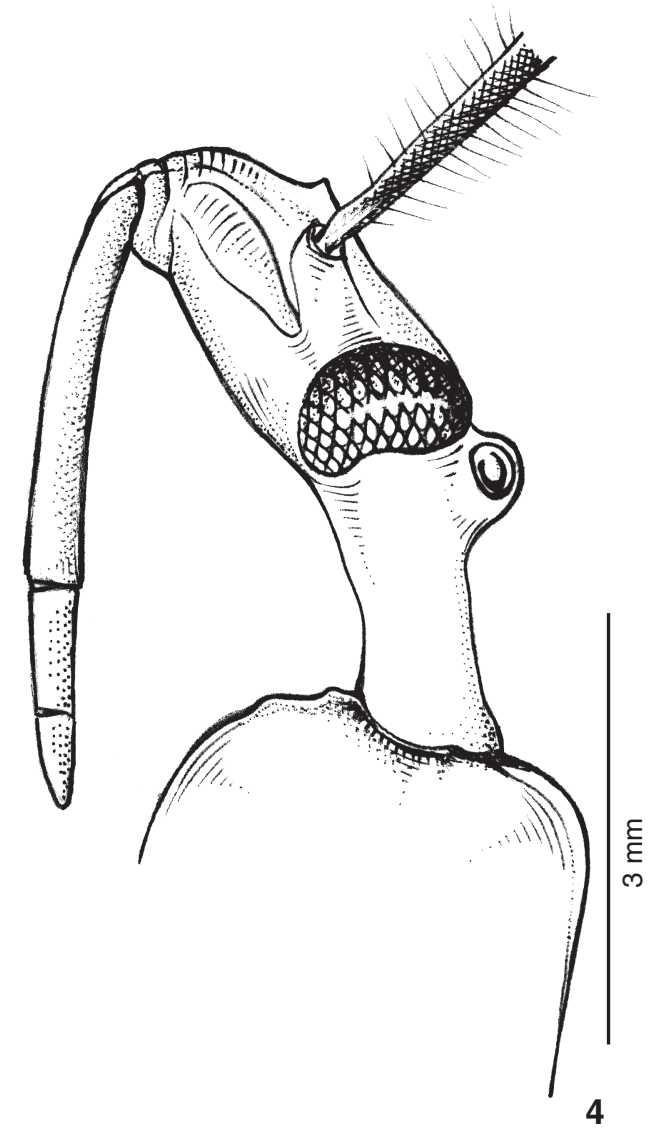

Figuras 1-6. Pothea furtadoi, sp. nov.: (1) holótipo, vista dorsal; (2) parátipo, vista dorsal; (3) cabeça, vista dorsal; (4) cabeça, vista lateral; (5) pronoto do holótipo, dorsal; (6) hemiélitros, escutelo e conexivo do parátipo, dorsal. 

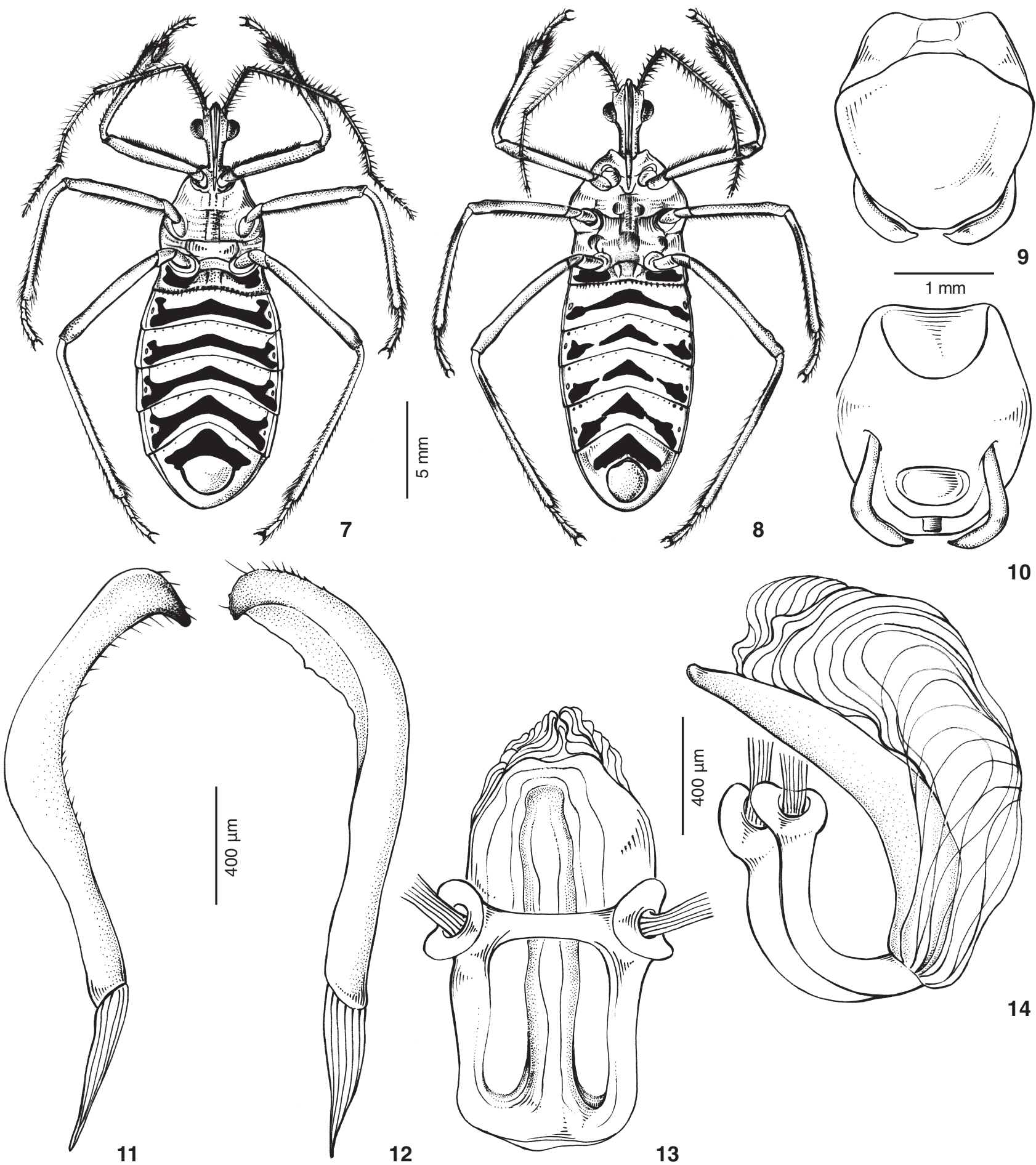

10

Figuras 7-14. Pothea furtadoi, sp. nov.: (7) vista ventral do holótipo; (8) vista ventral do parátipo; (9) pigóforo com parâmeros, vista ventral; (10)pigóforo com parâmeros, vista dorsal; (11) parâmero, vista ventral; (12) parâmero, vista dorsal; (13) falo, vista dorsal; (14) falo, endosoma exteriorizado, vista lateral. 
Tórax (Figs 1, 5 e 7). Vermelho a vermelho-rósea; com tegumento brilhoso, apresentando marcações enegrecidas na margem anterior, nos sulcos longitudinais, nas laterais da constrição transversa do pronoto (Fig. 5) e três manchas estreitas nas pleuras, a cada lado. Na região esternal um par de manchas escurecidas tênues junto à inserção das coxas medianas. Pronoto: ângulos umerais arredondados; sulco longitudinal liso no lobo anterior, iniciando-se na margem anterior, interrompendo-se antes do ponto médio, local com discreta elevação mediana. Constrição transversa do pronoto, sulcos laterais do lobo posterior e porção do sulco mediano longitudinal do lobo posterior representados por série de canalículos. No lobo posterior, o sulco mediano longitudinal não alcançando a margem posterior. Escutelo vermelho a vermelho róseo com o centro e as laterais escurecidas; com duas pontas curtas e pouco convergentes. Pernas: glabras, apresentando uma franja de pêlos finos na porção média da face inferior dos fêmures anteriores e médios e de todas as tíbias, formando tufo com elementos um pouco mais longos na porção apical; fêmures anteriores e médios um pouco espessados; fêmures posteriores finos com leve espessamento apical (Fig. 7). Tíbias finas com dilatação apical, mais desenvolvida no par anterior, apresentando fossas esponjosas apicais nos pares anteriores e médios à mesma altura da dilatação mencionada. Tarsos trímeros, alongados, com pêlos longos e finos. Todas as pernas vermelhas a róseo-avermelhadas com o ápice dos fêmures e tênue anel subapical no fêmur posterior escurecidos; tíbias com anel sub-basal e o ápice com escurecimento tênue; tarsos amarelo-alaranjados. Hemiélitros enegrecidos com veias do cório, a sua base e a borda lateral, excetuando o ápice, vermelhas ou róseo-avermelhadas (Figs 1 e 6).

Abdome (Figs. 1 e 7): conexivo vermelho. Esternitos com tegumento liso, glabro e brilhante; espiráculos elípticos; canalículos presentes na sutura intersegmentar entre os esternitos I e II, em toda a sua extensão e com pontuações esparsas nas laterais das suturas entre os esternitos II a VI. Esternitos amarelos com toda a borda externa, adjacente ao conexivo, avermelhada. Esternito I com faixas laterais enegrecidas; no holótipo observam-se faixas medianas largas e enegrecidas nos esternitos II a VI; essas faixas formam uma figura em "Y" em volta da região espiracular, nos esternitos II a V (Fig. 7). Cápsula genital roseada com o parâmeros escurecidos. Genitália do macho (Figs 9-14). Pigóforo subovalado, de coloração rósea (Figs 9 e 10). Parâmeros simétricos, alongados, digitiformes, afilados e escurecidos em direção ao ápice, apresentando alguns pêlos esparsos ventrais e apicais (Figs 11 e 12). Falo subretangular; placa basal desenvolvida, com os apêndices de fixação acoplados às suas extremidades superiores (Fig. 13). Endosoma com canal espermático alongado, largo e fortemente esclerosado e lóbulo membranoso e comprido (Fig. 14).

Distribuição geográfica. BrasiL, Mato Grosso e Minas Gerais.

Material examinado. Holótipo macho. Brasil, Mato Grosso: Alto Rio Arinos $\left(14^{\circ} 25^{\prime} \mathrm{W}, 5^{\circ} 29^{\prime} \mathrm{S}\right), 30 . \mathrm{IX} .2002$, E. Furtado leg.; Parátipo macho, BrasiL, Minas Gerais: Belo Horizonte $\left(19^{\circ}\right.$ 54’W, 4356'S), 06.X.1959, Evangelista leg. O material-tipo encontra-se depositado na Coleção Entomológica do Museu Nacional, Universidade Federal do Rio de Janeiro (MNRJ).

Etimologia. O nome da espécie foi dado em homenagem ao entomologista Eurides Furtado.

\section{DISCUSSÃO}

O parátipo apresenta coloração um pouco mais clara, vermelho-rosada, com as marcações do tórax e partes escuras das regiões centrais do cório mais tênues e restritas, observando-se maior distribuição da cor mais clara (Figs 2 e 6); as faixas ventrais dos esternitos são mais estreitas, interrompendo-se nos segmentos IV e V; na face lateral não formam a figura em "Y" mencionada no holótipo, só atingindo a porção posterior ao espiráculo (Fig. 8).

Pothea furtadoi sp. nov. diferencia-se de grande parte das espécies do gênero pelo tamanho $(21 \mathrm{~mm})$ e de todas as demais pelo conjunto de caracteres que reúne, a saber: coloração geral predominantemente vermelho a vermelho-róseo. Cabeça vermelha ou vermelho-rósea, clípeo com espinho dorsal (Fig. 4). Tórax vermelho a vermelho-róseo, apresentando marcações enegrecidas na margem anterior, nos sulcos longitudinais, nas laterais da constrição transversa do pronoto (Figs 1, 2 e 5) e três manchas estreitas nas pleuras, a cada lado. Constrição transversa do pronoto, sulcos laterais do lobo posterior e porção do sulco mediano longitudinal do lobo posterior representados por série de canalículos (Fig. 5). Pernas com uma franja de pêlos finos na porção média da face inferior dos fêmures anteriores e médios e de todas as tíbias (Figs 7 e 8). Todas as pernas vermelhas a róseo-avermelhadas com o ápice dos fêmures e tênue anel subapical no fêmur posterior escurecidos; nas tíbias observa-se anel sub-basal e o ápice com escurecimento tênue (Fig. 2). Hemiélitros enegrecidos ou escurecidos com nervuras do cório, a sua base e a borda lateral vermelhas ou róseo-avermelhadas e conexivo inteiramente vermelho (Figs 1, 2 e 6).

\section{AGRADECIMENTOS}

Aos entomologistas Eurides Furtado pela coleta e cessão do holótipo de Pothea furtadoi sp. nov. e Jean-Michel Bérenger (França) pela obtenção de material bibliográfico.

\section{REFERÊNCIAS BIBLIOGRÁFICAS}

Carpintero, D.J. 1978. Revisión del género Pothea Amyot \& Serville, 1843. Sus especies en la Argentina (Hemiptera, Reduviidae, Ectrichodiinae). Revista del Museo Argentino de Ciencias Naturales Bernadino Rivadavia, Buenos Aires, 5 (9): 177-286.

CARPINTERo, D.J. 1980. Nuevos Ectrichodiinae Americanos (Insecta, Hemiptera, Reduviidae). Acta Scientifica, Serie Entomología, Buenos Aires, 14: 3-33. 
Carpintero, D.J. \& J. Maldonado-Capriles. 1990. Contributions to the knowledge of American Ectrichodiinae. II. Notes about Rhiginia and Pothea (Hemiptera: Reduviidae). Journal of Agriculture of the University of Puerto Rico, San Juan, 74 (4): 449-456.

Carpintero, D.J. \& J. Maldonado-Capriles. 1996. Diagnostic characters and key to the Genera of American Ectrichodiinae (Heteroptera, Reduviidae). Caribbean Journal of Sciences, Mayagüez, 32 (2): 125-141.

Champion, G.C. 1899. Insecta Rhynchota. Hemiptera-Heteroptera, p. 229-243. In: F.D. Godman \& O. SALvin (Eds). Biologia Centrali Americana. Rhynchota. London, vol. 2, XIV+416p.

Dougherty, V. 1995. A review of the New World Ectrichodiinae Genera (Hemiptera: Reduviidae). Transactions of the American Entomological Society, Philadelphia, 121 (4): 173-225.

Lethierry, L. \& G. Severin. 1896. Catalogue général des Hémiptères. Berlin, Tome III, 275p.

Maldonado Capriles, J. 1990. Systematic Catalogue of the Reduviidae of the World (Insecta: Heteroptera). Caribbean Journal of Sciences, Special Edition, Mayagüez, 694p.
Putshrov, V.G. \& P.V. Putshrov. 1985. A Catalogue of the Assassin-Bugs Genera of the World (Heteroptera, Reduviidae). Kiev, Published by the authors, 137p.

SEHNAL, C. 2000. Typenkatalog der Reduviidae des Naturhistorischen Museums in Wien (Insecta: Heteroptera). Kataloge der wissenschaftlichen Sammlungen des Naturhistorischen Museums in Wien. Band 14. Entomologie, Heft 6. Wien, Naturhistorischen Museums Wien, 126p.

STÅL, C. 1864. Hemiptera nonnula nova vel minus cognita. Annales de la Société Entomologique de France, Paris, 4 (4): 47-68.

STÅL, C. 1872. Enumeratio Hemipterorum. Kongliga Svenska Vetenskaps-Akademiens Handlingar, Stockholm, 10: 66123.

van Duzee, E.P. 1916. Check list of the Hemiptera (excepting the Aphididae Coccidae and Aleurodidae) of America North of Mexico. New York, New York Entomological Society, XI+2+111p.

WYgoDZINSKY, P. 1949. Elenco sistematico de los reduviiformes americanos. Instituto de Medicina Regional de la Universidad Nacional de Tucumán, Monografia 1, 102p.

Recebido em 05.VIII.2004; aceito em 18.V.2005. 